\title{
A fracture equation of mixed mode cracks
}

\author{
xiangqiao yan $^{1}$ \\ ${ }^{1}$ Harbin Institute of Technology
}

May 23, 2021

\begin{abstract}
On the basis of the multiaxial fatigue limit equation by Liu and Yan, a fracture equation of mixed mode crack is proposed in this note. By means of the test data on the mixed crack fracture reported in literature, the fracture equation has been verified to be not only simple in computation but also high in accuracy.
\end{abstract}

\section{Hosted file}

crack-2021-1.docx available at https://authorea.com/users/301726/articles/523139-a-fractureequation-of-mixed-mode-cracks 